\title{
FOSTERING SELF- REGULATED LEARNING THROUGH DISTANCE EDUCATION: A CASE STUDY OF M.PHIL SECONDARY TEACHER EDUCATION PROGRAM OF ALLAMA IQBAL OPEN UNIVERSITY
}

\author{
Dr. Munazza AMBREeN \\ Secondary Teacher Education Department \\ Allama Iqbal Open University, Islamabad, Pakistan \\ Ambreen HAQDAD \\ Secondary Teacher Education Department \\ Allama Iqbal Open University, Islamabad, Pakistan \\ Wajid A. SALEEM \\ Department of Management Sciences \\ Iqra University, Islamabad, Pakistan
}

\begin{abstract}
Self-regulated learning (SLR) has been recognized as a pivotal antecedent of students' effective learning and academic achievement. A self-regulated learner can independently and effectively plan for learning, choose and use appropriate learning strategies and reflect and monitor learning progress. Self- regulated learning, for learners in general and for distance learners in particular, is inevitable for effectual learning process. Present study was focused to explore up to what extent distance education system is successful in fostering self-regulated learning among learners at higher level. An attempt was made to highlight the strategies used to foster self-regulated learning and students perceptions about effectiveness of these strategies. Views of teachers of distance education system were also sought to disclose their level of sensitivity, awareness and preferences for endorsement of self-regulated learning among students. Students of MS/M.Phil Secondary Teacher Education enrolled in Spring 2011 were taken as sample for the study. Focus group discussion and interviews were used as the tool for data collection. Data analysis revealed that teachers were very concerned about development of the skills required to regulate one's own learning among students of MS/ M.Phil program. Students considered the selflearning activities, assignments, presentations and reflection activities as very effective ones for transforming them into self-regulated learners. Moreover teachers were familiar with the potential factors that influence learners' ability to self-regulate their learning, in this context they suggested that more interactive course material and technology based assessment exercises can prove to be remarkable milestones on way to this destination.
\end{abstract}

Keywords: Self-regulation, learning, monitoring, reflecting, distance education 


\section{INTRODUCTION}

One of the major functions of education is to develop a person's abilities and skills necessary for lifelong learning. Every devoted educationist and every good education system wants students to become autonomous learners and thus continue lifelong learning process. But for this purpose learning opportunities according to the interest and values of the students and opportunities of self-direction, self-control and self-monitoring of learning are indispensable. Furthermore, for effective learning process the educational institutions must focus upon the enhancement of students' self-reflection, self-appraisal and self-efficacy beliefs and provide with flexible learning environments (Derrick, 2003). In short if our goal is life-long learning and students' autonomy as well as effective and efficient learning, one of the most important skills - the most important benchmark to this way is self-regulation of learning (or selfregulated learning).

Self-regulation as believed by Pintrich (2004) is an active as well as constructive process where learner sets goals for learning and then attempts to achieve these goals by monitoring, regulating, and controlling his/her behavior, cognition and motivation. On the other hand Zimmerman (2008) clarified that self-regulated learning should not be confused with potential for learning as he considered it to be different from mental ability or academic performance skill. Instead, it refers to a self-directed process through which learners transform mental abilities into task-related academic skills.

Zimmerman (2008) defined self-regulated learning as "learning that results from students' self-generated thoughts and behaviors that are systematically oriented toward the attainment of their learning goals." Self-regulated learning can also be described as an active process whereby learners construct goals for learning, monitor, regulate, and control their cognition, motivation, and behavior (Paris \& Paris, 2001). They are guided and constrained by their own goals and the individual characteristics of a particular learning environment. Self-regulatory activities affect individual students, their level of achievement, and the learning context. It is important, therefore, for students to learn how to learn and take control of their efforts (Wolters, 2011). Zimmerman (1989a, 1989b, 1990, 2001) identified three common features of most definitions of self-regulation.

$>$ Self-regulated learners are assumed to possess the knowledge of the potential usefulness of self-regulation processes in enhancing their academic achievement.

$>$ Second, self-regulated learning is characterized by a "self-oriented feedback" loop. This loop entails a cyclic process in which students evaluate the outcomes and determine the effectiveness of their learning strategies and respond to this feedback in a variety of ways, ranging from covert changes in self-perception to overt changes in behavior

$>$ The third feature is that most of the definitions of self-regulated learning provide an indication of how and why students choose to use a particular self-regulated process, strategy, or response.

\section{MODELS OF SELF REGULATED LEARNING}

There are numerous theories of SRL that differ in sometimes subtle and sometimes significant ways (Boekaerts et al., 2000; Zimmerman \& Schunk, Pintrich and Meece, 2008). Self-regulation learning model describes the specific cognitive processes that entail a learner's self-regulation through the definition of a task, the setting of goals and plans, the use of tactics to learn, and cognitive processes used to adapt learning both within the task and more globally. Winne (2009) posited that learning occurs in four basic phases namely: 
$>$ Task definition,

$>$ Goal setting and planning,

$>$ Studying tactics, and

$>$ Adaptations to metacognition

They described each of the four phases in terms of the interaction of a person's conditions, operations, products, evaluations, and standards. All of these aspects, except operations, are kinds of information that a person uses or generates during learning.

Self-regulated learning is controlled by an interconnected framework of factors that determine its development and sustainability (Bandura, 1993; Boekaerts, 1999; Pintrich, 2000; Zimmerman, 2008) and motivation is a critical factor in this framework (Kurman, 2001; Ommundsen, Haugen \& Lund, 2005; Wang \& Holcombe, 2010).

Rakes (2010) studied the influence of effort regulation as a self-regulatory skill, and intrinsic motivation on online graduate students and their levels of academic procrastination. He understood that both effort regulation and intrinsic motivation among online graduate students in this study had a significant influence on procrastination. Results of this study also indicated that as intrinsic motivation to learn and effort regulation decrease, procrastination increases. Since procrastination has a negative influence on student performance, the findings provide important information for online teachers trying to develop strategies that will improve student achievement in online courses.

In addition, both effort regulation and intrinsic motivation influence procrastination behavior are characteristics that can influence by online instructors in an effort to reduce procrastination. The results of this study indicate that together, these two factors powerfully influence procrastination.

Self-motivation occurs when a learner independently uses one or more strategies to keep themselves on-track toward a learning goal. It is important to the process of self-regulation because it requires learners to assume control over their learning (Corno, 1993). Furthermore, self-motivation occurs in the absence of external rewards or incentives and can therefore be a strong indicator that a learner is becoming more autonomous (Zimmerman, 2004). By establishing their own learning goals and finding motivation from within to make progress toward those goals, students are more likely to persist through difficult learning tasks and often find the learning process more gratifying (Wolters, 2011).

Research on the effects of academic self-regulation and motivation on learning has also revealed significant links between the two constructs (Schunk et al, 2008). Students with more developed self-regulatory cognitive skills are more likely to be more academically motivated and as a result learn more than others (Pintrich, 2003).

Self-regulated learners' proactive qualities and self-motivating abilities help to distinguish self-regulated learners from their peers. Research shows that self-regulated students are more engaged in their learning.

\section{Strategies to Foster Self-Regulated Learning}

Preparing students to become self-regulated learners, proficient in controlling the acquisition of knowledge, should be a recursive goal of teachers and students alike. Among the many skills that are involved in SRL, opportunities should be afforded for students to develop strategic reading and writing skills as well as providing for a rich environment of meaningful task engagement. 
Self-regulated learning consists of learning strategies such as cognitive, metacognitive, motivational and affective strategies influencing learning performance. Previous research has pointed out that task value was a good predictor of both cognitive and regulatory strategy use by students. Seventh- and eighth-grade students who valued and were interested in the content of the subject area were more likely to report using deeper processing strategies and more self-regulatory strategies (Pintrich, Roeser, \& De Groot, 1994; Wolters, 2011). , Research evidence shows that" self-regulated learning processes such as goal-setting, self-monitoring, and self-evaluation can be supported by using experience and resource sharing tools (e.g., blogs and wikis) whereas communication tools can enhance help seeking behaviors" (Debbagh \& Kitsantasl.,2012)

Self-regulated learning involves students using an array of cognitive and metacognitive strategies to manage and direct their learning (Pintrich, 1999; Zimmerman, 2001). Selfregulating students are assumed to be cognizant of their actions and able to control them in order to reach learning goals (Wolters, 2011). As students self-regulate, they are meta cognitively, motivationally, and behaviorally dynamic within their personal process of learning (Zimmerman, 1994). Eccles and Wigfield (2002) support this view by identifying three characteristics that self-regulated learners possess, such as cognitive strategy use, high levels of self-efficacy, and a variety of goals.

Employing higher thinking metacognitive reading and writing strategies, which foster selfregulated learning; students will need guidance from teachers on developing executive control strategies. Such executive control strategies may be planning and selecting the appropriate reading and writing strategies, monitoring them for problem solving, coordinating their usage and evaluating the entire process. These are more goal setting and goal directed. There are various ways discussed by researchers to use as effective strategies for fostering self-regulated learning among students.

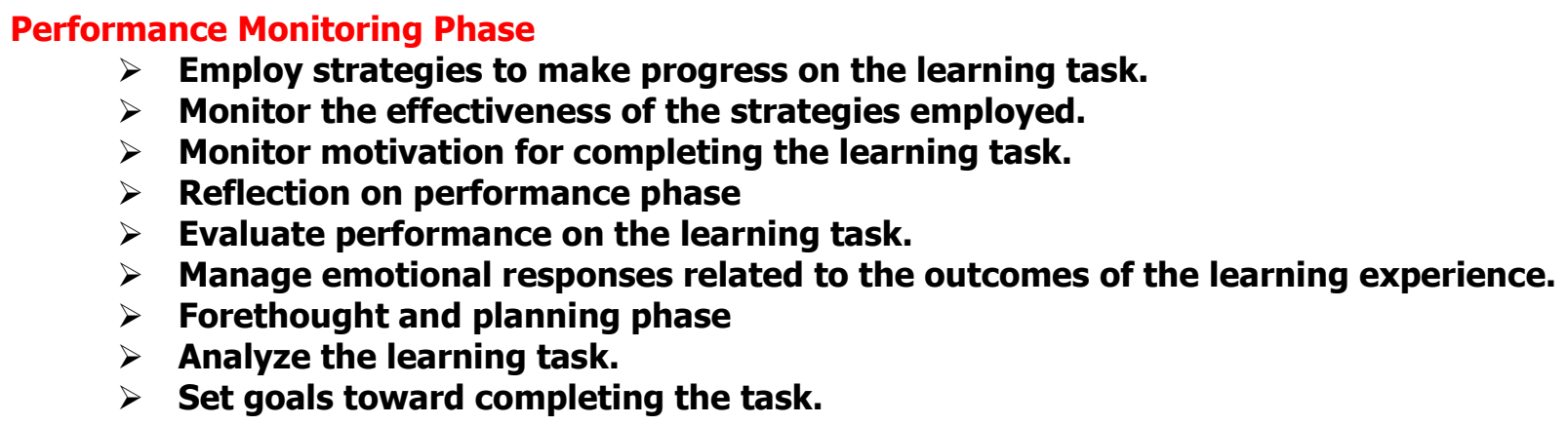

It is important for teachers to create a climate in the classroom that encourage students to activate strategy use in the construction of further knowledge. The climate will determine the amount of time the student will be engaged in self-regulated leaning and the time expended to the use of strategies to accomplish their goals. It will also contribute to the approach the students use in tackling a problem or project. If the environment is conducive to learning and the task are both challenging and fun, the student will become motivated to further inquire and discover the topic at a more advanced level. These activities must be open-ended, have variety, diversity, allow students to make choices about their journey through self-regulation, and provide for meaningful experiences. They should also have intrinsic value, a sense of ownership, and relate to students experiences. If these objectives are met, they will allow students to increase their retention and to transfer the learned skills to new context. 
There are many approaches that can be used to instill self-regulated learning in strategy usage for the development of reading and writing skills, the reciprocal teaching approach and the process of inquiry learning can be employed. Students can also be scaffolded with the necessary support to lead them to a more fruitful independent and self-regulated learning experience. The use of these approaches can be exhibited by social interaction of pair-shared activities, collaboration with children providing useful input into helping each other accomplish their goals, cooperative learning engagements, and children using discussion as a tool in planning strategic reading and writing skill.

Using the process of inquiry learning, the teacher can provide instruction and guidance on self-questioning into a particular inquiry surrounding the task of strategic reading and writing. He or she can further provide assistance with the investigative, creative, discussion and reflective aspect of the approach.

While the cognitive strategies are very important, they concentrate only on what to do and do not leave much room for any thinking about what to how, why, and when. They do not provide for explanation on what to expect from using the particular strategies I would provide instruction in developing the metacognitive executive control strategies. In addition to the declarative, procedural, and conditional knowledge, they also concentrate on the affective aspects of employing the strategies which include motivation and gaining a feeling of self-efficacy. It is necessary for students to know what outcomes to expect from using the various strategies and why it is important to monitor the strategies. Strategic reading and writing strategies should be used on an ongoing daily basis to allow for practice. They should be practiced in the context the teacher has created for the class and foster the usage of the strategies.

Understanding that factors outside of the teacher's control can have a major impact on the development of a student's ability to self-regulate also can prove to be a challenge. For example, how students choose to approach and monitor their learning is usually consistent with their preferred or desired social identity (Cleary \& Chen, 2009), which can have little to do with a teacher's instruction. Whereas students who believe getting good grades is inappropriate for their social group may disregard effective Self-Regulated Learning(SRL) strategies such as doing homework efficiently (Ommundsen et al., 2005), students with identities consistent with intellectual curiosity may be more apt to engage in self-regulated learning (Wang \& Holcombe, 2010). Ultimately, students' social identities can influence their academic behaviors and educational goals (Montalvo \& Torres, 2008).

\section{Self-Regulated Learning in the Context of Distance Education}

Research studies on the application of SRL in the context of distance education are limited. The few existing studies suggested three important dimensions of planning, monitoring and regulating, which facilitated self-learning. Rarely, the studies considered second-level dimensions to the first level factors (as noted above), which could further contribute to understanding the role of SRL in the context of distance learning that heavily depends on independent self-study.

\section{THE STUDY}

The present research aims to explore how much distance learning programs foster selfregulated learning skills among students. The study is a case study of $M$ Phil secondary teacher education program. For this purpose, students of $M$. Phil secondary teacher education program enrolled in session spring 2011 of AIOU, and five teachers (faculty members/ Resource Persons) for the said program were taken as sample of the study. 
The study used qualitative research methods to get in-depth knowledge and complete insight into the issue. The perceptions of students about their self-regulation and the ability of the distance education program to foster the self-regulation were checked by interviews. The sensitivity, awareness and preferences of teachers were analyzed through focus group discussions.

During the study 12 students of M Phil secondary teacher education were interviewed. The interview was semi structured. Focus group discussion was arranged among the five faculty members/ Resource persons of the secondary teacher education department. The discussion lasted for half an hour.

\section{RESULTS AND DISCUSSIONS}

The data of interviews and focus group discussion was triangulated to discuss the overall findings of the study. The M. Phil teacher education program is designed for distance learning. Both teachers and students appreciated the program and believed it to be helpful in enhancing students self-regulated learning skills by helping them in forethought, planning, performance monitoring and reflections on performance.

As one of the teachers stated during focus group discussion:

$M$ Phil program of AIOU is very much different from other regular universities program. The program is deliberately designed in a way that students go through the phases of self-regulated learning even if they have no prior experience of doing so.

The teachers were of the view that assignments sent to students, as an essential part of their degree requirements, play a vital role in enhancement of their self-regulated learning strategies. As one of the teachers added:

We design assignments in such a way that students have to go through certain process for their completion, for example they have to analyze the question, break it into different parts, plan for information sources and then they outline the answers.

During the assignments allocated to them they have to go through forethought and planning phase, for that purpose they analyze the learning task namely the assignment question and set specific goals towards completing it. When students are learning unfamiliar topics, they may not be aware of the best ways to advance on the task or of the goals being the most appropriate. Teachers and/or more experienced peers can tutor students on effective approaches in such problems. One of the teachers explained:

Students mostly approach us if a task is thought to be too much difficult to them. We help them chalk out the plan to make an outline of answer and guide them about sources which may help them. Sometimes we refer them to get help from excelling peers.

Then comes the performance monitoring phase, here, as revealed through interviews, the students utilize strategies to make progress on the questions that need creative answers and monitor the effectiveness of the strategies as well as their motivation for continuing progress toward the goals of the task. It was found that, if strategies are new, students sometimes slip back to using more familiar ones which may even be ineffective.

At the final stage of reflection on performance phase, students have to evaluate their performance in attempting the questions with respect to the effectiveness of the strategies 
that they chose. During this phase, students must manage their emotions about the outcomes of the learning experience. These self-reflections are of key importance which in turn influence students' future planning for upcoming assignments and goals, initiating the cycle to begin again.

The teachers of the program under study, during focus group discussion, agreed upon the need of inculcating self-regulated learning skills in distance learners. They also analyzed the program and had consensus that it is fostering SRL in learners to some extent. Teachers distinguished between the outcomes of self-regulated learners higher than those who lack in such abilities. It was observed by them that self-regulated learners possess proactive qualities as well as they are self-motivated which helps them to distinguish them from their peers. As a teacher shared her observations:

While checking the assignments the difference between self-regulated learners and otherwise is clear. Self-regulated learners have done the assignments in time, according to set pattern and gave logical answers.

The study results confirm many previous studies that showed that self-regulated students were proved to be more engaged in their learning. These learners commonly show certain behavior patterns. During interviews and discussion it was found that students of M.Phil Teacher Education Program were really engaged in their studies. They tend to finish up their assignments well before time.Their presentations are ready before the day to present and during discussions they seat themselves toward the front of the classroom (Labuhn, Zimmerman, \& Hasselhorn, 2010), voluntarily offer help to peers to answer questions (Elstad \& Turmo, 2010), and are always ready to search for additional resources regarding certain content (Clarebout, Horz, \& Schnotz, 2010).

Another feature of self-regulated learners is to maneuver their learning environments to meet their needs (Kolovelonis, Goudas, \& Dermitzaki, 2011). For example, teachers have found that self-regulated learners are apt to ask for advice (Clarebout et al., 2010) and information (De Bruin et al., 2011) and follow positive learning climates (Labuhn et al., 2010), than their peers who exhibit less self-regulation in the classroom. It is their resourcefulness and engagement, that findings of recent study suggest their better performance on academic tests and measures of student performance and achievement. It seems as though SRL can make the difference between academic success and failure for many students as is observed by previous researchers (Graham \& Harris, 2000; Kistner, Rakoczy, \& Otto, 2010).

\section{Motivational factor in Self-Regulated Learning}

Self-regulated learning depends on an interrelated framework of factors that establishes its development and sustainability. Motivation is a vital factor in this framework. For instance, a student told his way of working on a question:

When I read the question, it seemed not simple, it had many different parts, each requiring separate sources .So I must plan to deal with its parts and answer each part separately.

During the forethought and planning phase, when students think about why an assignment question should be responded and how much effort to put toward the details and analysis, their interests and ideals are factored into the decision. If students do not see value in learning goals put forth by given assignment, then they are less prone to spend much time setting goals and planning strategies to carry out those aims. One of the students told about his response to assignments: 
Sometimes the questions are not relevant, as I feel, if they have given "write a note on any random topic". I don't feel it much productive $I$ just search the topic and write everything given under the said heading.

Moreover, students' efficacy belief as well as their self-confidence to productively complete assignments has a role during the forethought and planning and performance monitoring phases in previous researches (Zimmerman, 2000). This research has also discovered selfefficacy and the use of self-regulation strategies to have automatic positive impacts on one another. Students with higher self-efficacy beliefs use more of self-regulation strategies and even the use of self-regulation strategies can escort one to amplification in self-efficacy beliefs and academic achievement.

During the performance monitoring phase, students incessantly appraise the meaningfulness of the learning assignment. Intrinsic motivation and preference guide the level of effort and persistence used in completing the assignment and use of other self-regulation strategies. As one of interviewee answered in the following way:

I really feel satisfied when I had planned and answered a technically tough question in the best possible way.

Finally, students' underlying attributions, which are the factors students attribute to their success or failure for a specific task, play a key role in the reflection on performance phase, as students make decisions of whether or not they will engage in an activity and utilize selfregulation strategies for similar activities in the future.

\section{Self-Regulated Learning: Strategies for Students}

Many strategies for students to foster self-regulating learning were identified through literature and were pointed out during interviews and focus group discussions as well. Direct instruction involves explicitly explaining different strategies to students, as well as how those strategies are used and what skills are involved in using those strategies (Zimmerman, 2008). The focus of this kind of instruction is modeling and demonstration. When teachers model and explain their own thought processes necessary for completing activities and assignments, students are more apt to understand and begin to use those same processes on their own (Boekaerts \& Corno, 2005). Though direct instruction may not be necessary for encouraging SRL in all students, it may be essential for most students. Research has shown that this type of instructions were part of M Phil syllabi. The teacher told:

The course for distance learning consciously has instructions to use selfregulated learning strategies

The students were even conscious of it, one of them added:

The books of the M Phil are different these are full of instructions as well as learning material; these are also guides how to learn.

Guided practice is another way teachers discussed to help improve SRL and motivation. During guided practices, the responsibility of implementing the learning strategy shifts from teacher to student. For example, a student might practice implementing a specific writing strategy while the teacher carefully observes and offers help when necessary

A student told in interview:

When the presentations were to be prepared the first time, I had to take guidance from teachers. But when I have done it first time the next ones were far easier for me to do them by myself. 
Independent practice should naturally follow guided practice. During this process, students are given opportunities to practice the strategy on their own, which can ultimately reinforce autonomy. The data indicated that once students were given SRL strategies to use, they were more likely to practice the strategies independently. Ideally, strategy instruction incorporates a combination of direct instruction and modeling, as well as guided and independent practice.

There are certain processes, when taught to students, especially those in distance learning mode. review of related literature has named the following : goal setting (Winne 2009), planning (Zimmerman, 2004; Zimmerman \& Risemberg, 1997), self-motivation (Corno, 1993; Wolters, 2011; Zimmerman, 2004), attention control (Harnishferger, 1995; Kuhl, 1985; Winne, 2009), flexible use of learning strategies (van de Broek, Lorch, Linderholm, \& Gustafson, 2001; Winne, 2009), self-monitoring (Butler \& Winne, 2009; Carver \& Scheier, 1990), appropriate help-seeking (Butler, 1998; Ryan, Pintrich, \& Midgley, 2001), and selfevaluation (Schraw \& Moshman, 1995). This study interviewed students and teachers to verify use of the processes mentioned in literature.

Students defined goals as the standards they had to achieve. They said that goals regulate an individual's actions. In the learning assignments, goals might either a good grade on an exam, or a broad understanding of a topic. Students shared that Short-term goals are attainable and are used to reach long-term ambitions. For example, if a student has a longterm goal to do splendid job in an exam, he or she might set attainable short term goals such as studying for a set amount of time and using specific study strategies to help ensure success on the exam. It was also suggested by teachers that encouraging students to 10 set short-term goals for their learning can be an effectual way to help students follow their progress. The syllabus of M Phil helped students use this goal setting strategy by giving them assignments for specific period of time. As a student explained:

I am glad that the questions are designed unit wise in assignments. I divide learning of units in accordance with assignment questions; short learning tasks seem easy and attainable. And slowly and gradually I go through the whole syllabi till the end of the semester.

After goal setting, planning can help students self-regulate their learning prior to engaging in learning tasks. In fact, the research indicated that planning and goal setting are paired processes, as planning can help learners establish well thought out goals and strategies to be successful. The students and teachers were of the view that Planning has at least three stages: establish a goal for a learning task, setting up strategies for achieving the goal, and finding out how much time and resources are required to accomplish the goal, same was stated in another study (Schunk, 2001). During focus group discussion one of the teachers added:

Our program teaches students to approach academic tasks with a plan which is a viable method for promoting self-regulation and learning. The learning tasks given in evaluation exercises need planning. If a student will be haphazard in his approach, he or she will end up in a mess only.

Furthermore, the distance education programs face the dilemma of the absence of external rewards or incentives and can therefore be a strong indicator that a learner is becoming more autonomous. Self-motivation occurs in these programs when students establish their own learning goals and find motivation from within to make progress toward those goals, students are more likely to persist through difficult learning tasks and often find the learning process more gratifying. The teachers were of the view that: 
Self-motivation occurs in M Phil program when students independently use one or more strategies to keep themselves on-track towards a learning goal. It is important to the process of self-regulation because it requires learners to assume control over their learning. We make the exercises creative a technically graded, students are gratified at each step they cover and are motivated to do the next.

Control over ones attention is a cognitive process that requires significant self-monitoring. Process entails clearing the mind of distracting thoughts, as well as seeking suitable environments that are conducive to learning. Research indicated that students' were satisfied by the capacity of the books to engage them in learning with focused time spent ontask. A student shared his observation as:

The books of the program are different from traditional ones. There are no long boring notes to read, but small passages followed by the tasks. So I never felt diverted and every new task grasped my attention.

One of the teachers indicated during discussion:

Teaching learners to attend to learning tasks is our priority. We help them to control their attention by removing stimuli that may cause distractions, and provide them with frequent breaks to help them build up their attention spans.

Successful learners are able to implement multiple learning strategies across tasks and adjust those strategies as needed to facilitate their progress towards their desired goals it is noted that most students were aware of and comfortable with different learning strategies. To use new strategies they were ready for appropriate amounts of scaffolding during practice. Teachers helped learners become independent strategy users.

During discussion on scaffolding, the teachers had consensus that:

The M Phil degree requires a bit different learning strategies from past habits of students; it needs more research oriented approach. We give students tips to switch over from traditional learning strategies to research oriented ones.

The students were also having the same view. Most of them, more or less responded in the following way:

I was first confused how to tackle this new approach, I mean the researches, the references, the bibliography, it was all too new for me. But during workshops the technically easy and sound ways of dealing all this stuff were explained in most of the lectures. Thank God now I feel comfortable with all this new learning.

Self-regulated learners are responsible for monitoring their progress towards learning goals. The process of self-monitoring in learners included self-monitoring of their progress on learning goals, planning ahead, self-motivation, focusing their attention on the task at hand, and use of learning strategies to assist their understanding. Teachers can encourage selfmonitoring by having students keep a record of the number of times they worked on particular learning tasks, the strategies they used, and the amount of time they spent working. This practice allows students to visualize their progress and make changes as needed. The teachers opinion that;

Such kind of tasks as to keep a record of the number of times they worked on specific learning tasks, the strategies they used, and the amount of time 
they spent working are provided and instructions are given to guide the students.

Students also agreed with the teachers' opinion as they get such tasks of keeping of records for their own sake.

Another outcome of the research was interesting and contrary to popular belief. It was that self-regulated learners do not try to attain every task on their own, but rather frequently seek help from others when necessary. An interviewee answered about help seeking in the following way:

I am not always clear about everything, and even can't take help from course in some problems, and then definitely I ask from my class fellows or contact teachers directly for help.

Teachers' discussion depicted the same. One of them clearly stated:

We always promote positive help seeking behaviors by providing students with on-going progress feedback that they can easily understand and allowing students opportunities to resubmit assignments after making appropriate changes.

Students were mostly trained for self-evaluation when they are able to evaluate their own learning through small exercises and checking the answers in the key given at the end of the books. This practice enables students to evaluate their learning strategies and make adjustments for similar tasks in their future. As a student described his observations:

I keep a regular check on my learning; I take care of time I spend on certain task. I also see that whatever I have learned through guidance, I should be able to use it in next task performance. If I do not check my own progress then I fear I won't learn up to the mark and in time.

In summary, self-regulated learners were found able to set short- and long-term goals for their learning, plan ahead to accomplish their goals, self-motivate themselves, and focus their attention on their goals and progress. They also are able to employ multiple learning strategies and adjust those strategies as needed, self-monitor their progress, seek help from others as needed, and self-evaluate their learning goals and progress based upon their learning outcomes. Teachers at the primary and secondary levels can use the aforementioned strategies to promote self-regulation in their classrooms. However, teachers should understand that learners develop at various paces, and strategies that work best for one learner may not always work with the next.

\section{Social Support and Feedback}

This study also found that social support from teachers and peers served an important role as students are learning to be more self-regulative. Findings from a study showed that task engagement and the use of SRL strategies was more common in students that regularly received support from their teacher and peers. Often, social support came in the form of feedback.

The teacher said in discussion:

We give prompt and positive feedback to students for their work as this will encourage their self-regulation in future.

Research indicates that effective feedback includes information about what students did well, what they need to improve, and steps they can take to improve their work. This type of 
feedback is often referred to as progress feedback. Not only can progress feedback assist students in improving their academic achievement, it also can promote student motivation and self-regulation. The student responded to a question about support in following way:

I'm so happy when I get appreciation note on $m y$ assignment from the teachers. I feel motivated to go for even better next time.

Another student added:

When I gave presentation, and it was followed by applause from my class and such positive comments from my teachers, I promised to myself that next presentation would be even better than this.

Results indicated that students who received feedback from their teachers were more likely to accurately use SRL strategies to improve their scores.

\section{Challenges to Promoting Self-Regulated Learning in the Classroom}

Though most teachers would agree that teaching students to be more self-regulative would be ideal, the practice does not come without challenge. Developing lessons that prepare students to engage in SRL practices and provide real support and opportunities for implementation is no small feat. Many will find that the major obstacle in helping students become self-regulative is the time required to teach students how to use specific strategies. Understanding that factors outside of the teacher's control can have a major impact on the development of a student's ability to selfregulate also can prove to be a challenge. For example, how students choose to approach and monitor their learning is usually consistent with their preferred or desired social identity, which can have little to do with a teacher's instruction. Whereas students who believe getting good grades is inappropriate for their social group may disregard effective SRL strategies students with identities consistent with intellectual curiosity may be more apt to engage in SRL learning.

The study revealed that teachers were very well aware of the fact that self-regulated learning is inevitable for distance learners' success. But at the same time they believed that teaching selfregulated learning strategies in distance education context is not an easy job. They discussed different ways to address these challenges. On important step in this regard was to provide interactive and thought provoking content and activities.

\section{CONCLUSION AND IMPLICATIONS}

This study indicated that distance education students have a relatively high level of selfregulation based on their own perceptions. Within the scope of the study, distance education students were interviewed to check them in terms of their self-regulating skills. Students reported to be at high level of self-regulating skills. The study also found differences in selfregulation skills based on academic achievement. Students with higher self-regulated learning strategies employed, academic achievement were found to report themselves higher in terms of self-evaluation and metacognition sub-dimensions. Therefore, it can be stated that self-evaluation and metacognition are important predictors of academic success at higher education. Teachers also indicated that the course of said program could be designed in more interactive form to promote self-regulated learning.

This study focused on one department at higher education level. In other studies, different students from different departments can be compared in terms of their ability to foster selfregulating skills and through these comparative studies different results may be obtained. This study aimed at getting a general overview of self-regulating skills of higher education students. In another study, researchers can focus on the factors that contribute to the development of selfregulating skills of students. 


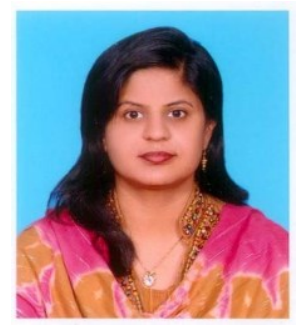

Dr. Munazza AMBREEN is currently working as Assistant Professor in secondary teacher education department of Allama Iqbal Open University, Islamabad, Pakistan. She has completed her Ph.D in education from National University of Modern Languages Pakistan. She is coordinator of M. Phil Teacher Education Program and is actively involved in M. Phil and Ph.D research supervision. Her special interest areas are teaching and learning strategies, quality assurance and enhancement in higher education, educational psychology, educational leadership and management.

Dr. Munazza AMBREEN

Assistant Professor

Secondary Teacher Education Department

Allama Iqbal Open University, Islamabad, Pakistan

Phone no: +923075045464, +929057713

E-mail: munazza.ambreen@aiou.edu.pk

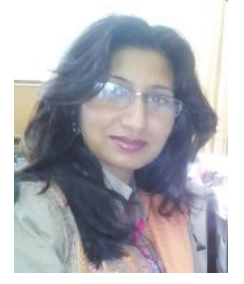

Ambreen HAQDAD is a Ph.D scholar in the Department of Secondary Teacher Education, Allama Iqbal Open University Islamabad Pakistan. She is serving as Teacher in English subject in Army Public School and College Rawalpinid. Her areas of interest in research are Teacher Education;

Ambreen HAQDAD

Ph.D Scholar

Secondary Teacher Education Department

Allama Iqbal Open University, Islamabad, Pakistan

Phone no: $\quad+923325526580$

E-mail: ambreenhaqdad@gmail.com

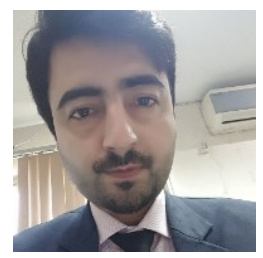

Wajid A. SALEEM is MS leading to Ph.D scholar in the Department of Management Sciences, Iqra University, Islamabad. He is serving as Assistant Director in Higher Education Commission in Islamabad. His areas of interest in research are School leadership, management practices, compensation management and servant leadership in educational institutions.

\section{Wajid A. SALEEM}

MS Leading to Ph.D Scholar

Iqra University, Islamabad, Pakistan

Phone no: $\quad+923135378584$

E-mail: wajidalisaleem.was@gmail.com 


\section{REFERENCES}

Bandura, A. (1993). Perceived self-efficacy in cognitive development and functioning. Educational Psychologist, 28, 117-148.

Boekaerts, M. \& Corno, L. (2005). Self-regulation in the classroom: A perspective on assessment and intervention. Applied Psychology: An International Review, 54(2), 199-231

Boekaerts, M. (1999). Self-regulated learning. International Journal of Educational Research, 31(6), 445-551.

Boekaerts, M. (2001). Context Sensitivity: Activated motivational beliefs, current concerns and emotional arousal. In S. Volet, \& S. Jarvela, S. (Eds.), Motivation in Learning contexts: theoretical and methodological implications. Pergamon Press.

Boekaerts, M., \& Cascallar, E. (2006). How far have we moved toward the integration of theory and practice in self-regulation? Educational Psychology Review, 18 (3), 199210.

Butler, D. L., \& Winne, P. H. (1995). Feedback and self-regulated learning: A theoretical synthesis. Review of Educational Research, 65, 245-281.

Butler, R. (1998). Determinants of help seeking: Relations between perceived reasons for classroom help-avoidance and help-seeking behaviors in an experimental context. Journal of Educational Psychology, 90, 630-643

Clarebout, G., Horz, H., \& Schnotz, W. (2010). The relations between self-regulation and the embedding of support in learning environments. Educational Technology Research and Development, 58(5), 573-587.

Cleary, T.J., \& Chen, P.P. (2009). Self-regulation, motivation, and math achievement in middle school: variations across grade level and math context. Journal of School Psychology, 47 (5), 291-314.

Corno, L. (1993). The Best-laid plans: Modern conceptions of volition and educational research. Educational Researcher, 22, 14-22.

Dabbagh, N., \& Kitsantas, A. (2012). Personal learning environments, social media, and selfregulated learning: A natural formula for connecting formal and informal learning. Internet \& Higher Education, 15(1), 3-8.

de Bruin, A.B., Thiede, K.W., \& Camp, G. (2011). Generating keywords improves metacomprehension and self-regulation in elementary and middle school children. Journal of Experimental Child Psychology, 109 (3), 294-310.

Derrick, M.G. (2003). Creating Environments Conducive for Lifelong Learning. Wiley Periodicals inc. Retrieved on 12 May, 2015 from

http://onlinelibrary.wiley.com/doi/10.1002/ace.115/epdf

Eccles, J.S \& Wigfield, A. (2002). Motivational Beliefs, Values and Goals. Annual Review Psychology, 53(1), 109-132.

Elstad, E., \& Turmo, A. (2010). Students' self-regulation and teacher's influence in science: Interplay between ethnicity and gender. Research in Science \& Technological Education, 28 (3), 249-260.

Graham, S. \& Harris, K. R. (2000). The role of self-regulation and transcription skills in writing and writing development. Educational Psychologist, 35(1), 3-12. 
Graham, S., \& Harris, K.R. (2005). Improving the writing performance of young struggling writers: Theoretical and programmatic research from the center on accelerating student learning. Journal of Special Education, 39 (1), 19-33

Harnishferger, K. K. (1995). The development of cognitive inhibition: Theories, Definitions, Research. In F. N. Dempster \& C. J. Brainerd (Eds.), Interference and Inhibition in Cognition. San Diego: Academic Press.

Kistner, S., Rakoczy, K., \& Otto, B. (2010). Promotion of self-regulated learning in classrooms: Investigating frequency, quality, and consequences for student performance. Metacognition and Learning, 5 (2), 157-171.

Kolovelonis, A., Goudas, M., \& Dermitzaki, I. (2011). The effect of different goals and selfrecording on self-regulation of learning a motor skill in a physical education setting. Learning and Instruction, 21 (3), 355-364.

Kuhl, J. (1985) Volitional mediators of cognition-behavior consistency: self-regulatory processes and action versus state orientation. In J. Kuhl and J. Beckman (eds) Action Control: From Cognition to Behavior. New York: Springer.

Kurman, J. (2001). Self-regulation strategies in achievement settings: Culture and gender differences. Journal of Cross-Cultural Psychology, 32 (4), 491-503.

Labuhn, A.S., Zimmerman, B.J., \& Hasselhorn, M. (2010). Enhancing students' self-regulation and mathematics performance: The influence of feedback and self-evaluative standards Metacognition and Learning, 5 (2), 173-194.

Montalvo, F.T., \& Torres, M.C. (2008). Self-regulated learning: Current and future Directions. Electronic Journal of Research in Educational Psychology, 2(1), 1-34.

Ommundsen, Y., Haugen, R., \& Lund, T. (2005). Academic self-concept, implicit theories of ability, and self-regulation strategies. Scandinavian Journal of Educational Research, 49(5), 461-474

Paris, S. G. \& Newman, R. S. (1990). Developmental aspects of self-regulated learning. Educational Psychologist, 25, 87-102.

Paris, S. G., \& Paris, A. H. (2001). Classroom applications of research on self-regulated learning. Educational Psychologist, 36, 89-91.

Pintrich, P. R. (2000). Multiple goals, multiple pathways: The role of goal orientation in learning and achievement. Journal of Educational Psychology, 92(3), 544-555

Pintrich, P. R. (2004). A conceptual framework for assessing motivation and self-regulated learning in college students. Educational Psychology Review, 16(4), 385-407.

Pintrich, P. R., \& Zusho, A. (2002). The development of academic self-regulation: Quarterly, 23(1), 7-25.

Rakes, (2010). Students' motivation and use of cognitive self-regulation strategies as predictors of procrastination in online courses. The University of Tennessee, Martin, Tennessee.

Ryan, A. M., Pintrich, P. R., \& Midgley, C. (2001). Avoiding seeking help in the classroom: Who and why? Educational Psychology Review, 13, 93-114.

Schraw, G., \& Moshman, D. (1995). Metacognitive theories. Educational Psychology Review, 7, 351-371.

Schunk, D. H., Pintrich, P. R., \& Meece, J. L. (2008). Motivation in Education: Theory, Research, and Applications (3rd ed.). N.J.: Pearson 
van den Broek, P., Lorch, R., Linderholm, T., \& Gustafson, M. (2001). The effects of readers' goals on inference generation and memory for texts. Memory \& Cognition, 29, 10811087

Wang, M.T., \& Holcombe, R. (2010). Adolescents' perceptions of school environment,

Winne, P. H. (1995). Inherent details in self-regulated learning. Educational Psychologist, 30, 173-188.

Winne, P. H. (2009). Self-regulated learning viewed from models of information processing. In B. J. Zimmerman \& D. H. Schunk (Eds.), Self-Regulated Learning and Academic Achievement, (2nd ed.). New York: Routledge.

Winne, P. H., \& Hadwin, A. F. (1998) Studying as self-regulated learning. In D. J. Hacker \& J. Dunlosky (Eds.), Metacognition in Educational Theory and Practice, The Educational Psychology Series. Mahwah, NJ: Erlbaum

Wolters, C. A., \& Pintrich, P. R. (1998). Contextual differences in student motivation and selfregulated learning in mathematics, English, and social studies classrooms. Instructional Science, 26, 27-47.

Wolters, C. A., Yu, S. L., \& Pintrich, P. R. (1996). The relation between goal orientation and students' motivational beliefs and self-regulated learning. Learning and Individual Differences, 8, 211-238.

Wolters, C.A. (2011). Regulation of motivation: Contextual and social aspects. Teachers College Record, 113(2), 265-283.

Wolters, C.A., \& Rosenthal, H. (2005). The relation between students' motivational beliefs and their use of motivational regulation strategies. International Journal of Educational Research, 33 (7-8), 801-820.

Zimmerman, B. (2008). Investigating self-regulation and motivation: Historical background, methodological developments, and future prospects. Educational Research Journal, 45(1), 166-183.

Zimmerman, B. J. (1989). A social cognitive view of self-regulated academic learning. Journal of Educational Psychology, 81(3), 329-339.

Zimmerman, B. J. (2000). Attaining self-regulation: a social cognitive perspective. In M. Boekaerts, P. R. Pintrich, \& M. Zeidner (Eds.), Handbook of Self-Regulation. San Diego: CA: Academic Press.

Zimmerman, B. J. (2004). Socio-cultural influence and students' development of academic self-regulation: A social-cognitive perspective. In D. M. McInerney \& S. Van Etten (Eds.), Big Theories Revisited. Greenwhich, CT: Information Age.

Zimmerman, B. J. (2008). Investigating self-regulation and motivation: Historical background, methodological developments, and future prospects. American Educational Research Journal, 45(1), 166-183. 